\title{
Pediatric-Type Follicular Lymphoma
}

National Cancer Institute

\section{Source}

National Cancer Institute. Pediatric-Type Follicular Lymphoma. NCI Thesaurus. Code C80297.

A nodal follicular lymphoma with favorable prognosis. It lacks BCL-2 rearrangement and $14 ; 18$ translocation. Nearly all cases are localized. It is usually seen in the pediatric population but similar lymphomas may occur in adults. 